Vol. 70, No. 2, pp. 167-184.

(C2004 Council for Exceptional Children.

\title{
Dimensions of Family
} and Professional Partnerships: Constructive Guidelines for Collaboration

\author{
MARTHA BLUE -BANNING \\ JEAN ANN SUMMERS \\ H. CORINE FRANKLAND \\ LOUISE LORD NELSON \\ GWEN BEEGLE \\ University of Kansas
}

\begin{abstract}
The development of collaborative partnerships between parents and professionals is too often unsuccessful. One reason for this failure may be the lack of empirical understanding of the components of interpersonal partnerships. Using qualitative inquiry, 33 focus groups were conducted with adult family members of children with and without disabilities and service providers and administrators. In addition, 32 individual interviews were conducted with non-English-speaking parents and their service providers. Indicators of professional behavior facilitative of collaborative partnerships were identified. These indicators were organized into six broad themes: (a) Communication, (b) Commitment, (c) Equality, (d) Skills, (e) Trust, and (f) Respect. The specific meaning of each theme is described, including similarities and differences between professionals and family members. Policy, practice, and future research implications are discussed.
\end{abstract}

For several decades, family and professional collaborative partnering has been considered a recommended practice in effective service provision for children with disabilities. Many authors identify the importance of family and professional partnerships (Adelman \& Taylor, 1997a, 1997b; Children's Aid Society, 1997; McKnight, 1995; Roberts, Rule, \& Innocenti, 1998). The significance of partnerships in educational planning is evident in public policy, research, and federal legislation (Epstein, 2001; Nisbet, Covert, \& Schuh, 1992; Osher \& Osher, 2002). The concept of collaborative partnership between parents and schools in the design and implementation of special education programs is one of six principles of the Individuals with Disabilities Education Act (IDEA) established by Congress (Turnbull \& Turnbull, 2000). Other federal laws (e.g., Goals 2000, Title I, the Elementary and Secondary Education Act, and Communities' and Children's Mental Health Systems Improvement 
Act) also emphasize the importance of ensuring partnerships between families and professionals (Epstein; Osher \& Osher). There is increasing recognition that fostering collaborative partnerships with families leads to early dispute resolution and the prevention of more costly actions such as mediation, due process hearings, and litigation (Feinberg, Beyer, \& Moses, 2002).

In other words, early intervention should not only engage parents as collaborative partners while they receive services, but it should also prepare parents to become effective partners with special services they encounter as their child grows older.

In early intervention, the term "family centered" describes recommended practices characterized by emphasis on family strengths, encouraging family choice and control over decisions about services, and collaborative relationships between parents and professionals (Bruder, 2000). Early intervention programs that are evaluated as being more "family focused" (i.e., that engage in meaningful partnerships between families and professionals) tend to foster a stronger sense of personal control and self-efficacy in parents (Trivette, Dunst, Boyd, \& Hamby, 1995) and result in greater parent satisfaction with services (Applequist \& Bailey, 2000). Bailey, McWilliam and colleagues (1998) noted that the expected outcomes for families of early intervention should include helping families gain a positive view of professionals and the special services system, and enhancing the family's perceived ability to work with professionals and advocate for services. In other words, early intervention should not only engage parents as collaborative partners while they receive services, but it should also prepare parents to become effective partners with special services they encounter as their child grows older.

Research indicates that parents and professionals alike define collaborative partnerships at least in part in terms of the quality of their interpersonal relationships with each other (McWilliam, Tocci, \& Harbin, 1998). In a review of literature on service integration,
Park and Turnbull (2003) created a framework distinguishing interpersonal and structural components of effective partnerships. They identified from the literature a series of interpersonal relationship attitudes, skills, values, and beliefs that appear to contribute to effective partnerships among families, professionals, and agencies. Interpersonal relationships among Early Head Start staff, Part C early interventionists, and parents were also found to be at the heart of effective collaboration in a five-state study of Early Head Start and Part C collaboration (Summers et al., 2001). Collaborative partnerships characterized by factors such as trust, respect, communication, shared vision, and cultural sensitivity were identified as critical for effective partnerships with families in decision making about augmentative communication (Parette, Brotherson, \& Huer, 2000), inclusion (Soodak \& Erwin, 2000), and serving children with problem behaviors (Park \& Turnbull, 2002). Research also indicates that teachers favor interactions with parents that go beyond superficial, highly prescriptive notions of "parent involvement" (McWilliam, Maxwell, \& Sloper, 1999; Sanders, 1999). In short, forging supportive relationships between parents and professionals appears to be at the heart of a collaborative partnership (Dinnebeil, Hale, \& Rule, 1996, 2000).

In spite of legislation and the desires of parents and professionals, development of collaborative partnerships is too often unsuccessful (e.g., Rainforth, York, \& Macdonald, 1992; Salembier \& Furney, 1998). In early intervention, where family-centered services have been recommended practice for more than 3 decades, its general implementation remains elusive (Bruder, 2000). Although professionals favor collaborative interactions with parents, research indicates that a gap exists between actual practice and professionals' desires to do their best (McWilliam et al., 1999; Sanders, 1999). Blue-Banning, Turnbull, and Pereira (2000) conducted focus groups with parents and professionals to examine facilitative factors in the achievement of visions for Latino adolescents and young adults with disabilities. Both stakeholder groups identified the disparity of 
power and authority in the relationship between parents and professionals as a major challenge to successful partnerships. At the heart of their comments was the point that parents were not seen as equal partners and that professionals maintained control. These findings, along with the results of other. studies (Allen \& Petr, 1996; Harry, Rueda, \& Kalyanpur, 1999; Jones, Garlow Turnbull, \& Barber, 1996; Turnbull \& Turnbull 2001), indicate that a central problem in the development of partnerships is failure to establish collaborative, trusting, empowering relationships between families and educators that support effective service delivery.

One reason for the gap between recommended practices for collaborative partnerships and the implementation of those practices may be the failure to operationally define the construct of partnership to allow for investigation and documentation of benefits associated with partnership relationships (Dunst, 2000). This lack of empirical understanding of the components of interpersonal partnerships impedes the ability to form consensus and develop meaningful accountability about partnerships in the field. It also impedes development of personnel preparation programs that both promote effective practices for fostering partnerships between families and professionals (Winton, 2000) and encourage understanding and sensitivity across increasingly diverse cultures represented among families in special education (Kalyanpur \& Harry, 1999; Lynch \& Hanson. 1998; Sileo \& Prater, 1998). In other words, lack of development in both research and personnel preparation makes it difficult to implement collaborative partnerships because professionals do not know, in operational ways, what is expected of them. It is possible that deeper understanding of family members' and professionals' perspectives of the "meaning" of factors such as mutual respect and trust could lead to better guidelines for practice. What, for example, are the specific actions parents interpret as "respect"? Beyond practice implications, understanding of the specific, measurable indicators that comprise the "meaning" of these intangible qualities should lead to more effective evaluation of support and educational programs.

The most appropriate tool for exploring and refining the meaning of partnerships from the perspectives of the partners is qualitative inquiry (Cresswell, 2002). Qualitative research has become increasingly acceptable in special education research. Pugach (2001) called for the use of qualitative research to move beyond individual case stories to an understanding of the broader socio-cultural context that recognizes the diversity of parent voices. Sandall, Smith, McLean, and Ramsey (2002) reviewed qualitative research in the field of early intervention and concluded that, although qualitative research accounts for a small proportion of studies published in that field, the numbers are on the rise in the last 44 years. They noted that qualitative research is particularly suited to "providing a 'voice' for the various stakeholders ... by listening to their voices and considering their voices within the full context of their experiences" (Sandall et al., p. 135). To understand the meaning of collaborative relationships, the "stakeholders" are families from diverse backgrounds, families both with and without children with a disability, and professionals and administrators. This research was designed to trace the common, culturally accepted threads of meaning and the specific actions, attitudes, and behaviors that comprise that meaning, to move toward a more measurable consensus about the meaning of collaborative partnerships. The present study, which is a component of a larger qualitative study, was designed to explore the question: What specific indicators of professional behavior do parents and professionals identify as indicative of collaborative partnerships?

\section{METHOD}

Focus groups served as the primary data collection method to obtain a descriptive understanding of the components of positive partnerships. In addition, we conducted in-depth individual interviews with families with limited English proficiency and with professionals who support these families. The study was conducted in Kansas, North Carolina, and Louisiana.

\section{PARTICIPANTS}

Focus Groups. Focus groups were the primary data source for this study because we wanted to encourage participants to share ideas and perceptions with one another and thus to gener- 
ate a broad range of possible factors related to positive partnerships (Krueger \& Casey, 2000; Marshall \& Rossman, 1995). The initial sampling plan was to conduct two rounds of family member focus groups and two rounds of professional focus groups in each community with the same respondents. However, due to attrition and expressed interest by other community members, participants in Round Two focus groups ncluded a mixture of Round One participants and some new respondents. Round One focus groups were intended to identify primary components of collaborative partnerships. The purpose of the second round of focus groups was to verify/check member responses and clarify unresolved questions.

The investigators identified community-site coordinators in each of the three locations. These coordinators helped us establish a purposive selection plan that was individually responsive to each community (Fetterman, 1989). Only research developed within the context of a specific geographic area can reflect the community realities it strives to investigate (Massey, Zambrana, \& Bell, 1995).

The research team and community-site coordinators identified the family member focus group break characteristics (i.e., those that differentiated groups from each other) for each site. These included parents of children with and without disabilities, race/ethnicity, and income. Participants" children in the "with disabilities" groups represented a variety of disability classifications. All parents had children who ranged in age from 3 to 21. Two professional focus groups were conducted in both Round One and Round Two - one for direct service providers and one for program administrators from education, health, and social service agencies in the community. Service provider/program administrator participants were identified by the community-site coordinators as professionals who maintained strong collaborative partnerships with families they supported.

Individual Interviews. To ensure perspectives of culturally and linguistically diverse families, the research team conducted in-depth individual interviews with 18 families with limited English proficiency who have children with disabilities, and with 14 professionals providing direct services to families with limited English proficiency. These interviews were conducted in the Kansas site only, because resources for translators were limited at the other two sites. Using purposive sampling, the research team worked with social service agencies, public school English as a Second Language Programs, and a family support program, to identify family and professional participants. The 18 family members included 1 Vietnamese, 1 Hmong, and 16 Latino families.

We hoped to create a profile of partnership components that identified common themes across a wide range of cultural, geographic, and socioeconomic points of view.

Participant Demographics. We hoped to create a profile of partnership components that identified common themes across a wide range of cultural, geographic, and socioeconomic points of view. Therefore, although we had no intent to compare points of view, we tried to ensure that diverse voices could be heard among our participants. Among both focus group and interview participants, a total of 137 family members were included. Among family members, $72 \%$ (99) were female. One focus group included 8 individuals with disabilities; among the remaining 129 participants, (a) 101 (79\%) were biological parents, (b) $8(6 \%)$ were adoptive or foster parents, and (c) $6(5 \%)$ were other family members (e.g., grandparent, sibling). There was a range of ethnic distribution, including (a) 64 (41\%) African American, (b) 23 (17\%) Latino, (c) 41 (30\%) White, and (d) 6 (4\%) Other. Eighty (67\%) family members were between the ages of 30 and 60 , with $24(18 \%)$ under age 20 and 2 over age 60 . Seventy $(51 \%)$ of the family members were employed full or part-time. Among the 101 participants reporting income levels, there was relatively even distribution of annual income levels: (a) $37 \%$ less than $\$ 25,000$, (b) $34 \%$ between $\$ 25,000$ and $\$ 50,000$, and (c) $21 \%$ more than $\$ 50,000$. For the 70 family members who had a child with a disability, (a) $27 \%$ of the children were preschool aged, (b) 36\% were elementary, (c) $19 \%$ were secondary aged, and (d) $7 \%$ were postsecondary aged. The reported levels of severity of their child's disability included $42 \%$ mild, $45 \%$ moderate, and $4 \%$ 
severe or very severe. (Numbers in these demographic categories do not add up to 137 participants because some participants left some questions blank or did not return their demographic questionnaire. Because we are not analyzing these qualitative data to determine differences among the groups, missing data in the demographic profiles are not a relevant issue for the research.)

For the 53 professional participants in the focus groups and interviews, $48(91 \%)$ were female. There were $17(32 \%)$ administrators and $36(70 \%)$ direct services providers. They were working in the fields of (a) education $(n=13$, $25 \%)$, (b) human/social services $(28,53 \%)$, (c) health care $(9,17 \%)$, or (d) a combination of fields $(3,6 \%)$. The majority $(\mathrm{n}=36,70 \%)$ were White, with $17(32 \%)$ African Americans represented.

\section{INTERVIEW PROTOCOL}

An interview guide provided direction for both the focus groups and the interviews. In the indi vidual interviews, a research team member participated with a translator. Although the questions used in both formats were established a priori, they were open-ended, allowing participants latitude to supply the depth and breadth of information they wanted to give (Stewart \& Shamdasani, 1990). In the focus groups, the framework for questioning followed general guidelines for facilitating focus group discussions. That is, the discus sion began with an opening question designed to help participants connect, followed by explanatory or introductory information about topics and purposes of the session, followed by key questions, and finished by presenting summarizing or "wrap-up" questions designed to clarify and solicit any additional thoughts (Krueger, 1998). Participants were asked to think of examples of successful partnerships between professionals and parents and to describe what made hem successful; they were similarly asked to describe examples of unsuccessful partnerships. Facilitators adapted questions as needed to enable the direction of discourse to be shaped by participants (Stainback \& Stainback, 1989). Probes expanded on an issue or clarified a respondent's meaning. After each ofthe first six focus groups, facilitators debriefed to discuss which questions were most effective, and revised probes accordingly.

For Round Two focus groups, we developed a handout including a list of emergent themes from the Round One transcripts. Participants were asked to react to these themes, comment on their accuracy and relevance to themselves, suggest additional factors that were missing from the list, and expand or elaborate on their understanding of the meaning of those factors.

\section{DATA COLLECTION}

Focus Groups. The 34 focus groups each lasted approximately 22 hours. Lunch or a light dinner was provided to promote a relaxed environment and encourage interaction within the group (Krueger \& Casey, 2000). The community-site coordinators also attended most focus groups as observers to further enhance a sense of openness (Stewart \& Shamdasani, 1990).

Two researchers conducted each focus group, with the lead researcher facilitating discussion. The second researcher operated the audio tape recorder and took accompanying notes, including key discussion points, notable quotes, and group dynamics. The researchers gave an overview of the study, distributed and explained the consent forms, and discussed the importance of maintaining the privacy of comments made within the group. Finally, the researchers distributed gift certificates to an area store for $\$ 20$ to the family-member group participants. Service providers and administrators were not paid for their participation. In some locations, agency policies forbade professionals from taking incentive or extra pay for participation in the course of their duties; in others, the groups refused payment. Reimbursement for child care, as well as transportation, was also provided for families who needed those supports.

Individual Interviews. We held individual interviews in locations identified by respondents as most comfortable for them. Some were held in their homes, others in the school or clinic where the family was served. The translators were not connected with the school or service agency working with the respondent. A member of the research team asked the interview questions. The 
translator then translated the interview questions and the participants' responses. Thus, the researcher could use a probing and conversational style similar to that used by facilitators in the focus groups.

\section{DATA ANALYSIS}

The primary objective for including diverse participants in the focus groups and interviews was to ensure that the concepts generated represented a wide range of possible points of view. Individual respondent comments were not coded with any demographic marker (e.g., ethnicity, income level), as this was not relevant to the purpose of this research. Therefore, responses of participants from different backgrounds were not compared, However, because professionals and family members represented different transcripts, it was possible to compare their respective comments in the course of our analysis. The variations and commonalities in their responses will be highlighted in our results.

Coding. All focus groups and individual interviews were transcribed verbatim. Investigators reviewed transcripts of sessions they had facilitated or interviews they had conducted and corrected transcription errors. Transcripts of interviews and focus groups were imported into Ethnograph, a qualitative analysis software program designed to organize and retrieve data. The four-member research team read eight transcripts independently and then together discussed perceived themes. These themes were given code names to be recognized by Ethnograph, along with a definition for each code. This produced a list of codes and their definitions, called the "codebook."

Next, research dyads from the research team analyzed a group of 16 transcripts using the initial codebook. The researchers in each dyad read their assigned transcripts independently, then met to discuss and reach consensus on their findings. New themes or recommended changes were reported to and discussed by the full research team. This process produced a revised codebook for use in analysis of the next round of transcripts. Having repeated this process iteratively through the first 24 transcripts, revisions to the codebook were becoming rare; therefore, the remaining 44 transcripts were divided among the team members and coded individually, with the team meeting weekly to discuss any emerging changes or additions to the codebook. A total of 11 versions of the codebook were successively developed through this process.

We entered the coded transcripts into Ethnograph. For each of the coded categories, investigators pulled reports from Ethnograph that contained segments (usually a paragraph of narrative or a comment by one participant) of all transcripts receiving that code. Dyads of team members reviewed a set of reports, (a) checking for agreement/disagreement concerning the accuracy of the coding, and (b) generating sub-codes for the larger categories. The four-member analysis team then discussed their findings.

Category Reduction. After confirming the codes and code definitions, we placed individual definitions of each code on index cards. As a group, the team sorted the codes as they appeared to relate to each other. Because the focus of this study was on specific behaviors and attitudes of professionals required for positive partnership, those categories or comments not related to interpersonal components of positive partnership were set aside for later analysis. The final data reduction process involved clustering categories into larger themes of partnership. In some cases, two or more closely related individual codes were collapsed. The individual categories were conceptualized as indicators for the broader thematic area in which they were included. Definitions of these indicators were revised and clarified to make them as concrete as possible. The final result of this process was a total of 39 categories or indicators organized into 6 broad themes.

\section{VERIFICATION}

Trustworthiness was verified throughout the study using a variety of strategies. These included (a) multiple data sources, (b) multiple researchers and analysts, (c) verbatim transcripts, (d) coding checks, and (e) member checks at the end of each focus group. A final verification strategy, a comprehensive member check, allowed participants to evaluate the interpretive fairness and validity of the research team's analysis (Guba \& Lincoln, 1989; Patton, 2001; Seidman, 1991). Each participant was sent an executive summary of the interpretations and conclusions drawn from the focus groups and individual interviews, along with a cover letter; a one-page response form; and a self-addressed, 
stamped envelope. The research team conducted follow-up calls to participants who did not respond to the member check document. Participants were asked (a) if the summary was a reasonable interpretation of their perspective as well as their assessment of the group they represented, and (b) whether important points were left out. Responses did not suggest any significant revisions to the results.

\section{RESULTS}

Table 1 provides an overview of the six themes of Collaborative Family-Professional Partnership, along with their respective indicators or subcategories. Indicator categories contain responses by both family member and provider/administrator participants. The relative emphasis or proportion of responses in the given categories by professionals versus family members is not reported because, in qualitative research, a numerical weight to numbers of responses is not meaningful (Patton, 2001). Further, because there were fewer professional/administrator focus groups and interviews, there were more opportunities for family members to generate additional comments around the same themes. Still, as we present the findings, we will note differences and similarities in meanings and emphases given to each domain by professionals and family members.

It is important to note that the majority of comments made by both professionals and family members focused on indicators of professional behaviors that contribute to a collaborative partnership, because that was the stated question of our research study and the orientation of our interview protocols. All the groups, however, did make a few comments about parental contributions to the partnership, and we will discuss these where they occur. However, this report reflects the focus of our study on what professionals, agencies, or policies needed to do to ensure high-quality partnerships.

Another salient point of these findings is that in all domains, both positive and negative examples of the same concept were presented.
This was in part an artifact of the interview protocol, in which we asked participants to think of examples of both successful and unsuccessful partnerships. In initial versions of our codebooks, we coded comments describing positive experiences with a "+," and those describing negative experiences with a "-." However, as the coding struc ture evolved, it became apparent that in all cases, we had both positive and negative examples of the same constructs. Therefore, the "+" and "-" categories were collapsed. Again, we will present both positive and negative examples of the developed categories.

Finally, we should emphasize that the categories we developed are highly interrelated. Often, a comment would include a string of descriptors related to several themes, and therefore was coded in each of the relevant categories. Communication was seen as a vehicle for establishing trust, expressing respect, and conferring equality for families. Being a skilled professional with state-of-the-art competencies was also linked to a sense of professional commitment. The six categories presented are not proposed as orthogonal variables, but as interrelated and containing potentially measurable indicators of professional behaviors and attitudes contributing to positive partnerships with families.

family members stressed that communication should be honest and open, with no hidden information and no "candy-coating" of bad news.

\section{COMMUNICATION}

Parent Comments. Not surprisingly, study participants emphasized heavily the importance of communication to positive partnerships. Partici pants described the need for quantity in communication (i.e., that communication should be frequent and open). More often, however, comments concentrated on the importance of the quality of communication. That is, family members stressed that communication should be honest and open, with no hidden information and no "candy-coating" of bad news. However, tact was perceived as important. Being tactful meant being sensitive to information that should be conveyed 
TABLE I

Six Themes of Collaborative Family-Professional Partnership With Related Indicators

\begin{tabular}{ll}
\hline Collaborative Partnership Theme & Indicators \\
\hline Communication: The quality of & Sharing resources \\
communication is positive, understandable, & Being clear \\
and respectful among all members at all & Being honest \\
levels of the partnership. The quantity of & Communicating positively \\
communication is also at a level to enable & Being tactful \\
efficient and effective coordination and & Being open \\
understanding among all members. & Listening \\
& Communicating frequently
\end{tabular}

Commitment: The members of the partnership share a sense of assurance about (a) each other's devotion and loyalty to the child and family, and (b) each other's belief in the importance of the goals being pursued on behalf of the child and family.

Equality: The members of the partnership feel a sense of equity in decision making and service implementation, and actively work to ensure that all other members of the partnership feel equally powerful in their ability to influence outcomes for children and families.

Skills: Members of the partnership perceive that others on the team demonstrate competence, including service providers' ability to fulfill their roles and to demonstrate "recommended practice" approaches to working with children and families.

Trust: The members of the partnership share a sense of assurance about the reliability or dependability of the character, ability, strength, or truth of the other members of the partnership.

Respect: The members of the partnership regard each other with esteem and demonstrate that esteem through actions and communications.
Demonstrating commitment Being flexible

Regarding work as "more than a job"

Regarding child and family as "more than a case"

Encouraging the child and family

Being accessible to the child and family

Being consistent

Being sensitive to emotions

Avoiding use of "clout"

Empowering partners

Validating others

Advocating for child or family with other professionals

Allowing reciprocity among members

Being willing to explore all options

Fostering harmony among all partners

Coming to the table/avoiding "turfism"

Acting "equal"

Taking action

Having expectations for child's progress

Meeting individual special needs

Considering the whole child or family

Being willing to learn

Being reliable

Keeping the child safe

Being discreet

Valuing the child

Being nonjudgmental

Being courteous

Exercising nondiscrimination

Avoiding intrusion 
in private, avoiding implications of blame, and remembering to include positive comments about a child as well as the challenges. Communication, according to these participants, should also be clear and free of jargon.

Other comments related to the need for families, as well as all members of the service team, to have access to information about resources. Families added another point that this information should be coordinated or organized in such a way that they have easy access to it. For example, participants in several focus group sessions described multiple times when they had "stumbled" on information they thought was critical for their child, or when they had not learned until much too late that a particular resource was available. The sense that they had "stumbled" onto in formation rather than having it presented to them systematically left parents worried that there was other information "out there" that they had not been provided. One father noted, "I was never told about [the clinic] and I accidentally happened to have fallen into the ... center." Another parent, whose son did not receive needed services until young adulthood, identified the disparity of communication in one agency as compared to others:

My experience has been if they have been hospitalized in City Hospital there is a strong network of communication that is filtered to the parents. However, other private facilities do not give that information.... Very few of them will refer you to associated agencies or just to a network to get you started.

Finally, participants emphasized the need for communication to be two-way, that is, for professionals and parents to listen carefully and nonjudgmentally to what the other has to say. As one father put it:

The first thing is to listen to us ... because we know our kids better than anybody.... I think some of these people have preconceived notions about everything.... So if I tried to say, to tell them [professionals] something, it'd be LISTEN TO ME.

Professional Comments. Professionals also emphasized the importance of frequent and honest communication with families, and, like parents, talked of the need to listen carefully and respectfully. Many professionals said they needed to avoid jargon in their communication. They also emphasized the need to check tactfully to make sure that all parents, especially possible nonreaders, understood the reports, description of rights, and other documents they were receiving.

You're going over your paperwork and you notice, you're looking at them, they're not reading. And then you [think],..." Oh, this man can't read or not read very well".... And then you can tell the therapist on the file without, you know, causing any embarrassment and they can get ways to show them the information.

Like parents, professionals also highlighted the need to share information. One professional described how sharing information was an important tool in building trust with families:

I think another way that we build partnerships with our parents and the team is - well, with me, I talk a lot.... I give them so much information.... They're really grateful about that because no one else really gives them that much information.... They trust me now, you know, and I can help them better if they trust me.... I build a lot of relationships through a lot of talking and giving them information and that's important to them.

\section{COMMITMENT}

Parent Comments. The study participants emphasized strongly that they wanted professionals in their partnerships to demonstrate commitment and dedication to their work. Participants made repeated statements that professionals should consider working with children and families to be "more than a job," or "more than just a paycheck," or that families and children should be seen by the professional as "more than a case," or "more than a number." In other words, a committed professional was defined as one who values the relationship with individuals he or she serves as much or more than the tangible career rewards of the job. Many parents emphasized that a committed professional should recognize the importance of their relationship with parents as well as with the children:

[My son's teacher] came to my house to meet with me. That just meant so much to me that she would take time out of her day to come to my house - 
before she left the house she gave me her pager number, her home number ... in all the previous schools not one teacher gave me their home phone number - so I think one of the characteristics of these [collaborative profes sionals] is that they truly, truly have a genuine interest into the well-being of that child and they believe that in order to serve the child properly they have to have a close personal relationship with the parent. They can't educate just the child academically; they really have to get into the workings of the family.

Some family member participants went beyond this level to say they wanted a professional to be "like a member of the family," and illustrated this comment by describing friendships they had established with one or more service providers.

Family participants also talked of appreciating professionals who demonstrated "above and beyond" commitment in "little" ways. Examples were being willing to meet with them outside the regular working day, remembering their child's birthday or bringing materials from home to work with the child. Some parents thought that simply speaking to the parent when they crossed paths while shopping or in other community settings, was evidence of the professional's commit ment.

Professional Comments. Professionals also echoed the "more than a job" theme discussing requirements for working with families and also for working with other professionals on a team. Some professionals defined "going the extra" mile as persistence, (i.e., re-contacting parents who were hesitant about enrolling in a service program, and giving them time to decide whether to access a service). Others described commitment as doing "whatever it takes" to meet needs, regardless of their job description:

It's like I'm not in this field for the money. If you work for a nonprofit, you're not in it for the money.... So, often times, I'm working with a parent on the IEP, which certainly isn't in my job description. Or I'm giving them SSI information.... Sometimes we need to take those stringent hats off.... I've gone to IEP meetings. I've gone to people's homes when they couldn't get in to see me and needed a counseling session. So I just sign out for lunch. the committed professional thinks of his or her job more as a calling "I'm not just a therapist; I'm an advocate for persons with developmental disabilities."

This comment illustrates the theme expressed by professionals and parents alike that commitment is demonstrated by thinking of clients as people rather than cases. It also illustrates the view that the committed professional thinks of his or her job more as a calling: "I'm not just a therapist; I'm an advocate for persons with developmental disabilities." It is this sense of their work as a "calling" that makes them think of their work - as the parents put it - as "more than a paycheck." Participants identified professionals who met only the "letter of the law" as obstacles to partnerships: "Another barrier is the people that fulfill [only] the letter of the law and not the spirit, so that they run in and get the minimum amount done, and then they're out."

\section{EQUALITY}

Parent Comments. The study participants emphasized that partnership requires equality or reciprocity between families and service providers. An equal partnership includes a sense of harmony or ease in the relationship. Family members often expressed this concept by describing positive relationships with professionals who they considered "down to earth," as in this mother's description:

\footnotetext{
She's very educated ... but you would never know it.... You know, some people when they have those degrees, they are here up in the air and you know, "You be little, you beneath me." But she's not that type of person. She's a downto-earth person.
}

Beyond simply promoting an easy or harmonious- relationship, the study participants believed that establishing equality required active effort from professionals to empower families. They described the importance of having professionals acknowledge the validity of parents' points of view, as opposed to discounting or ignoring them. They also 
described the need for professionals to empower families by actively encouraging them to express opinions and helping families gain skills to enable them to participate fully in decision making. The importance of this is exemplified in a father's negative experience:

Our experience is that if it's a partnership, it's not a partnership of equals. It's professionals who DON'T listen and think they know every thing or are afraid to admit they don't know everything. On the other hand, it's parents who've been taught that they need to build a support team, they need to network, they need to get everybody on the same page, but it's very frustrating not to be able to do that if you're ... not being listened to.... We have more information on our son's disability than they do. They either can't or won't admit that.

Finally, parents also described positive relationships with professionals who "went to bat for" their child or who "stuck their neck out" to advocate for services.

This theme also includes descriptions of the importance of equality among members of a team or group engaged in planning. Among family participants, the commonly used expression for this concept was "come to the table," as in "people who work together should be ready to come to the table," meaning professionals should collaboratively contribute their ideas, responsibilities, and resources.

Professional Comments. Professionals expressed the same "coming to the table" concept in their discussions, using the term "turfism" to describe members of the team who failed to collaborate fully or who had hidden agendas. These comments occurred primarily in discussions of inter- or intra-agency partnerships, rather than in reference to relationships with families. The following comment from a professional focus group participant exemplifies that failure to form a common ground based on equality can be destructive to a partnership:

I can remember one situation specifically where a student was extremely emotionally disturbed but one person on the team ... saw his [the student's] issues as much more behavior than everyone else and she was basically consequencing behaviors instead of understanding the underlying mental illness.... There was no one on that team who could convince her any differently. She just got very dug in and she felt that she was the expert.... So one of the things that makes a team function poorly is when somebody gets very territorial or very proprietary.

Like parents, professionals also talked about the importance of empowering parents to participate as equals in deciding on services for their child and family. This was not always an easy task, as many professionals viewed the system as "set against" the parent:

If you are going to be successful, all the players have to be involved, and everybody has to be equally respected around the table, and I don't get that sense that parents of exceptional children ... are at that point yet [because of the system].

Because of a general belief that parents were disadvantaged in terms of the partnership due to obstacles created by the system, professionals spent considerable time discussing the need to empower parents and their strategies for doing so. Professionals described informing parents of their rights, helping parents compile a list of questions for the doctor, guiding them in expressing their opinions, or simply going to a meeting to serve as moral support:

"If you are going to be successful, all the players have to be involved, and everybody has to be equally respected around the table, and I don't get that sense that parents of exceptional children.. are at that point yet [because of the system]. "

There's been a lot of times that I have gone to, you know, any number of types of meetings with a parent, and never said a word. It's just that if somebody else [is] in that room with the parent, [it] makes them [the parents] feel like they didn't have to be afraid to say something.

It was often at this point in the discussion, however, that professionals expressed concern that there may be a thin line between empowering parents and fostering too much dependency. In several groups, the professionals 
discussed ways to avoid crossing that line by helping parents assume responsibility for their own advocacy:

I get paged constantly by one mom, you know, "I'm going to the doctor, what do I need to ask today?"... I mean, I've become this fixture for this mom to always be the interpreter and go-between between any other services, and ... I need to back her off.

\section{SKILLS}

Parent Comments. Examples of positive. (or negative) partnerships often included observations about skills or competence of service providers. Family members admired professionals whom they perceived could "make things happen," in terms of concrete help for their child or their family. There were also numerous descriptions of professionals who had been skilled or confident enough to adapt instructional approaches to meet a child's unique needs. Parents also wanted professionals to have high expectations for their children and provide appropriate challenges to ensure their children's progress. One parent described how a professional gently pushed her to expect more of her child:

We babied [my daughter] more than we should have. I would carry her. Her teacher told me, "Put her down, make her walk." She was stricter, she was teaching us. [She said], "You can't feed her. You have to let her feed herself." All these things we would do out of convenience, you know... She said, "No, you have to make her do it." And that's someone who is far beyond a teacher, she is someone who truly cared about our child.... I want [professionals] to give me re alistic expectations of what my child can do, but at the same time help me to push her to be at her fullest.

Family members also admired providers who were willing to learn and keep up to date with the technology of their field. For these participants, a competent professional is someone who is not afraid to admit when he or she does not know something, but-an important caveat-is willing to find out. One father praised a service provider with whom he worked:

If she doesn't know anything, she makes sure she finds out.... When you ask a question, she makes sure that you get a response to it. And yeah, she's not scared to tell us up front, you know, "I don't know." Which is one thing that I appreciate.... Tell me you don't know and get the information back to us.

Professional Comments. Most professional comments that were coded in the "skills" category were focused on intra- or interagency partnerships, rather than partnerships with parents. These comments about the skills they wanted their colleagues to have were very consistent with qualities parents wanted for all professionals. For instance, professionals talked about the importance of team members who were up to date in their fie ld, who were willing to try new ideas, who were able to adapt approaches to meet individual needs, and who were interested in continuing to learn:

For these participants, a competent professional is someone who is not afraid to admit when he or she does not know something, but - an important caveat - is willing to find out.

Some people don't like [trainings] ... because we have so much paperwork. We still have to see clients in order to bill, so then you got these trainings that have to take place, but the trainings are beneficial because a lot of time, you get a chance to network and find other people who know things that you didn't know.

Discussions about skills also focused on the importance of developing a whole-child, whole-family orientation to services. As one professional put it, "If we keep in mind that we're all in the in terest of the child.... We have to bring everyone to the table. We've got to have that partnership to know that WHOLE child. To service that WHOLE child."

\section{TRUST}

Parent Comments. Trust is a term often used in the literature related to developing positive relationships between providers and families (e.g., Dinnebeil et al., 2000). Parent participants used the term "trust" in the context of three distinct meanings. First, trust meant reliability, in the sense that people who are trustworthy can 
be depended upon to follow through with an action, do what they say they are going to do, or otherwise fulfill promises. One parent illustrated reliability this way: "If you tell me you're going to do something, do it.... don't tell me [you are] going to do this and don't do it and don't tell me you did it when you didn't - just don't tell me an untruth."

Second, trust meant safety (i.e., parents wanted to trust that their child could safely be left with a service provider without fear of physical or emotional harm). This meant not only making sure the child is clean, warm, fed, and protected, but also making sure the child is treated with dignity and protected from such "hurts" as teasing peers.

Third, trust included discretion. Some participants gave both positive and negative examples of partnerships in which professionals could be trusted with confidential or personal information about the family, or in which professionals violated their confidence.

Professional Comments. The theme of reliability was also an important factor for professionals:

I think it really comes back to trust. And to the kind of trust that you can establish with that family so that they KNOW that this is a person they can depend on to give them, if not the answer, then to help them find it wherever it exists. Or just to be that listening ear. Maybe there isn't an answer to what the problem is, but at least there's somebody there who isn't going to judge them.

In another example, in the midst of a discussion about the general challenges of working with physicians, one group of multidisciplinary professionals noted a particular doctor in their community who was a positive exception in his dependability. To illustrate her point about how "good" he is, one participant said, "And he even returns phone calls to parents!" Professionals also talked about discretion in establishing trust with families:

It's purely a matter of trust, that they can trust that person so that they can tell them whatever. I have heard all kinds of things you know, from families and from the children that I work with, and I'd consider that pretty sacred, actually. It's kind of a compliment as far as I can see that they're willing to trust me with those kinds of things.

\section{RESPECT}

Parent Comments. Respect emerged as an essential component of partnerships. "Respect" is a term often used in the partnership literature but seldom defined. We probed extensively for clarification of participants' meaning of this term. For many participants, "showing respect" meant valuing the child as a person rather than as a diagnosis or a disability label:

If they perceive someone as being less than human then they are going to treat that someone as an object. . . I want [my son] to. . feel like he belongs to the human race, like there's a place for him, like he fits in.

If they perceive someone as being less than human then they are going to treat that someone as an object.... I want [my son] to ... feel like he belongs to the human race, like there's a place for him, like he fits in.

Additionally, "respect" for these participants often meant simple courtesy: (a) calling parents by their last names or asking permission to use a given name, (b) be ing on time for meetings, (c) acknowledging parents' contributions and efforts with respect to their child, and so on. The fact that common courtesy is sometimes lacking in family-professional partnerships was illustrated by a number of examples of treatment the families considered discourteous. This is evident in the following comment:

I had to leave my job to go to the [IEP] conference .... Do you want to know how many educators came in and had me sign something and walked out.... It's like you're just being brushed through like an assembly line. Or they were like scanning you through the grocery line. And then they leave.

Professional Comments. Professionals talked of respect in terms of "building respect," or 
establishing respect" with families. To them, respect meant accepting a family "where they are," or displaying a nonjudgmental attitude toward the family. A nonjudgmental attitude included both valuing people from different cultural backgrounds, and being nonjudgmental about a family's lifestyle. One professional summed it up this way:

\begin{abstract}
We have had people who would go into a home and they'll come back and say, "Oh, this child should be taken out of this home. This home is just filthy.... " Well, okay ... first of all, no home has to be as clean as yours is [Laughter]. Second of all, what is it that's keeping this family from keeping their home as neat as maybe THEY would like it to be?... What are the underlying things? You CAN'T be judgmental about that and you can't expect families to live by what your standards are.
\end{abstract}

Professionals also talked of respect for families in the context of describing other agencies that they perceived as disrespectful to families. This was particularly the case when they discussed helping the families they served in their struggles with "the bureaucracy," or "the system":

Here we go again with the bureaucracy ... because they are so condescending. I mean half the time, I don't dress like a [professional] ... and I'll go into a place and they will treat me very rude and then if I say "I'm here on a so-and-so case," "Oh!" And then it's a whole different story, "Well then, how can I help you?"... [Because they thought I was a client] I could've sat there and stared at the window for 20 minutes before somebody might even make eye contact.

These professionals thought this lack of respect displayed by some programs was responsible for a great deal of damage to families, ranging from loss of their sense of empowerment, to an unwillingness to access services because of the stigma and humiliation attached.

\section{DISCUSSION}

\section{IMPLICATIONS FOR FUTURE RESEARCH}

The purpose of this research was to increase understanding of the indicators of professional behaviors associated with collaborative partnerships from the perspective of parents and professionals. The intent was to give "voice" to their experiences and provide a context for understanding, rather than to infer or generalize to a larger population. As a qualitative study, the primary value of this report is in exploring the meanings and perceptions participants ascribe to the actions of professionals; in other words, to understand what the term "positive partnership" between professionals and families brings to mind. We have identified a series of specific behaviors and attitudes that these respondents think of when they hear broader terms such as "respect," "communication," and "commitment." For example, "trust" is a vague concept, but the identified indicators of being re liable/dependable, creating a safe environment for a child, and maintaining discretion are behaviors which can be observed and measured in a rela tively objective way. Their comments provide a "grounded theory" foundation for the development of observable measures and selfassessment tools for professionals.

Development of a measure of positive partnerships is a next step in this research, first, because it will provide a way to validate the general applicability of this qualitative study. Second, such a measure will have broad policy and program application for assessing the quality of the partnerships in schools or communities. If we have a way to measure the components of positive partnerships reliably, we will have a viable outcome measure for assessing the value of training as well as models for intervention with children with disabilities and their families.

The agreement between parents and professionals about what constitutes positive behavior on the part of professionals is fairly remarkable. Both parents and professionals, in their separate groups, generated comments about the importance of communication, commitment, equality, skills, respect, and trust for successful relationships to occur. The differences were often a matter of the degree of emphasis rather than a conflict in basic values.

One difference in emphasis was in discussions of commitment and equality. Parents talked of wanting professionals to "go the extra mile" and to be "like family" in their involvement with them. Professionals expressed these same sentiments, but they also expressed reservations about taking these concepts too far. 
These reservations centered around the perceived need to "empower" families to take charge of advocating for their child and themselves, and the concern that doing "too much" might foster co-dependency and actually harm the family. The questions of when being "like family" gets in the way of doing one's job, and when "empowering" becomes disenfranchising, are issues about the boundaries between families and professionals. These issues have not been well researched. Further study is needed to explore how to create effective guidelines for appropriate boundaries between parents and professionals that preserve warm and committed relationships without disempowering families.

The focus of this study was on the responsibilities of professionals to ensure collaborative partnerships. It should be considered a parallel contribution to the literature on parental responsibilities, most commonly referred to as "parent involvement." The parent involvement literature for both general and special education contains numerous references to expectations for parents with respect to home and school relationships. In general education, for example, Epstein (2001) lists six components in a framework for home-school relationships, including such elements as sending children to school ready to learn, participating in events at the school, helping with homework, and so on. In special education, both policy and the literature outline additional responsibilities for parents to advocate for their child's special needs and to participate in decision making through development of the individualized education program (Turnbull \& Turnbull, 2001). Future research might investigate whether enhancing the specific interpersonal skills and attitudes of professionals, as identified in this study, results in enhanced parent involvement in educational programs.

\section{IMPLICATIONS FOR PRACTICE}

The results of this study underscore the point that common sense and ordinary human decency are at the heart of positive partnerships between families and professionals serving children with disabilities. The types of behaviors and attitudes these study participants suggest as the compo- nents of positive partnerships on the whole do not require a major investment in new resources for education or other service systems. The results of this study also suggest that great strides toward improving practice with families can be accomplished through relatively inexpensive means. For example, schools might use these concrete indicators to provide more training to professionals on developing high quality relationships with families.

The results of this study underscore the point that common sense and ordinary human decency are at the heart of positive partnerships between families and professionals serving children with disabilities.

A series of dialogues between parents and professionals, using these indicators, might also result in greater understanding and progress toward more satisfying relationships. Discussion between parents and professionals in each community or school setting is important because it provides an opportunity for clarification of the meaning of terms like "respect," "trust," and "commitment" in the context of the given community. It also provides an opportunity for parents and professionals to understand each other's points of view. Professionals need to hear directly from families their stories about how various actions or inactions have impacted their family, and about how well intentioned actions or comments did or did not have their intended effect. On the other side, parents need to hear and experience professionals' perspectives about how and why certain actions were taken, and what the limitations of their own lives might be. As these participants noted, most parents are perfectly willing to be "reasonable" when they have enough information to allow that to happen.

The policy and practice implications of a viable method to measure the quality of relationships are extensive. Outcome-based evaluation of services is increasingly important in a growing climate for accountability in education and other human services. Certainly in education, the ultimate outcomes are 
improved academic achievement and functional life skills; for families, the ultimate outcomes are improved quality of life for their children with disabilities and for themselves. However, these study participants repeatedly emphasized that for them the quality of their partnerships with service providers was a critical element of their overall quality of life. Time and again, these participants referred to the stress and exhaustion caused by the perceived necessity to fight for services, cope with humiliating or disrespectful regulations or provider attitudes, or otherwise deal with breakdowns in their relationships with professionals. These results lead us to suggest that the quality of partnerships might be conceptualized as one additional outcome for which programs should be held accountable. At the very least, the quality of partnerships between families and professionals might be conceptualized as an intermediary outcome or one of several critical prerequisites for successful student and family outcomes.

\section{REFERENCES}

Adelman, H., \& Taylor, L. (1997b). Toward a scaleup model for replicating new approaches to schooling. Journal of Educational and Psychological Consultation, 5, 197-230.

Adelman, H. S., \& Taylor, L. (1997a). Addressing barriers to learning: Beyond school-linked services and full service schools. American Journal of Orthopsychiatry, 67, 408-421.

Allen, R. I., \& Petr, C. G. (1996). Toward developing, standards and measurements for familycentered practice in family support programs. In G. H. S. Singer, L. E. Powers, \& A. L. Olson (Eds.), Redefining family support: Innovations in public private partnerships (pp. 57-86). Baltimore, MD: Brookes.

Applequist, K. L., \& Bailey, D. B. (2000). Navajo care givers' perceptions of early intervention services. Joumal of Early Intervention Services, 23, 47-61.

Bailey, D. B., McWilliam, R. A., Darkes, L. A., Hebbeler, K., Simeonsson, R. J., Spiker, D., \& Wagner, M. (1998). Family outcomes in early intervention: A framework for program evaluation and efficacy research. Exceptional Children, 64, 313328.

Blue-Banning, M. J., Turnbull, A. P, \& Pereira, L. (2000). Group action planning as a support strategy for Hispanic families: Parent and professional perspectives. Mental Retardation, 38(2), 262-275.

Bruder, M. B. (2000). Family -centered early intervention: Clarifying our values for the new millennium. Topics in Early Childhood Special Education, 20, 105-115.

Children's Aid Society. (1997). Building a community school (Rev. ed.). New York: Author.

Creswell, J. (2002). Research design: Qualitative, quantitative, and mixed methods approaches. (3rd ed.) Thousand Oaks, CA: Sage.

Dinnebeil, L. A., Hale, L. M., \& Rule, S. (1996). A qualitative analysis of parents' and service coordinators' descriptions of variables that influence collaborative relationships. Topics in Early Childhood Special Education, 16, 322-347.

Dinnebeil, L. A., Hale, L. M., \& Rule, S. (2000). Early intervention program practices that support collaboration. Topics in Early Childhood Special Education, 19, 225-235.

Dunst, C. J. (2000). Revisiting "Rethinking early intervention." Topics in Early Childhood Special Education, 20, 95-104.

Epstein, J. L. (2001). School, family, and community partnerships: Preparing educators and improving schools. Boulder, CO: Westview Press.

Feinberg, E., Beyer, J., \& Moses, P. (2002). Beyond mediation: Strategies for appropriate early dispute resolution in special education. Unpublished manuscript. National Center on Alternative Dispute Resolution (CADRE): Eugene, OR.

Fetterman, D. M. (1989). Ethnography: Step by step (Applied social research methods series, Vol. 17). Newbury Park, CA: Sage.

Guba, E. G., \& Lincoln, Y. S. (1989). Fourth generation evaluation. Newbury Park, CA: Sage.

Harry, B., Rueda, R., \& Kalyanpur, M. (1999). Cul tural reciprocity in sociocultural perspective: Adapting the normalization principle for family collaboration. Exceptional Children, 66, 123-136.

Jones, T M., Garlow, J., Turnbull, H. R., \& Barber, P A. (1996). Best practices: Empowerment in a family support program: Program, professional, and policy is sues. In G. H. S. Singer, L. E. Powers, \& A. L. Olson (Eds.), Redefining family support: Innovations in public-private partnerships (pp. 87-114). Baltimore: Brookes.

Kalyanpur, M., \& Harry, B. (1999). Culture in special education: Building a posture of reciprocity in parent-professional relationships. Baltimore, MD: Brookes. 
Krueger, R. A. (1998). Analyzing and reporting focus group results. Thousand Oaks, CA: Sage.

Krueger, R. A., \& Casey, M. A. (2000). Focus groups: A practical guide for applied research (3rd ed.). Thousand Oaks, CA: Sage.

Lynch, E. W., \& Hanson, M. H. (1998). Developing cross-cultural competence: A guide for working with children and their families (2nd ed.). Baltimore, MD: Brookes.

Marshall, C., \& Rossman, G. B. (1995). Designing qualitative research (2nd ed.). Thousand Oaks, CA: Sage.

Massey, D. S., Zambrana, R. E., \& Bell, S. A. (1995). Contemporary issues in Latino families: Future directions for research, policy, and practice. In R. E. Zambrana, (Ed.), Understanding Latino families: Scholarship, policy, and practice (pp. 190-204). Thousand Oaks, CA: Sage.

McKnight, J. (1995). The careless society: Community and its counterfeits. New York: Basic Books.

McWilliam, R., Maxwell, K., \& Sloper, K. (1999). Beyond involvement: Are elementary schools ready to be family-centered? School Psychology Review, 28(3), 378-394.

McWilliam, R. A., Tocci, L., \& Harbin, G. L. (1998). Family-centered services: Service providers' discourse and behavior. Topics in Early Childhood Special Education, 18, 206-221.

Nisbet, J., Covert, S., \& Schuh, M. (1992). Family involvement in the transition from school to adult life. In F. R. Rusch, L. DeStefano, J. Chadsey-Rusch, L. A. Phelps, \& E. Szymanski (Eds.), Transition from school to adult life: Models, linkages, and policy (pp. 408424). Sycamore, IL: Sycamore.

Osher, T W, \& Osher, D. M. (2002). The paradigm shift to true collaboration with families. Journal of Child and Family Studies, 11(1), 47-60.

Parette, H. P., Brotherson, M. J., \& Huer, M. B. (2000). Giving families a voice in augmentative and alternative communication decision-making. Education and Training in Mental Retardation and Developmental Disabilities, 35, 177-190.

Park, J., \& Turnbull, A. P (2002). Families speak out: What are quality indicators of professionals in working with children with problem behavior? Journal of Positive Behavior Interventions, 4, 118-123.

Park, J., \& Turnbull, A. P. (2003). Service integration in early intervention: Determining interpersonal and structural factors for its success. Infants \& Young Children, 16, 48-58.
Patton, M. Q. (2001). Qualitative evaluation and research methods (2nd ed.). Newbury Park, CA: Sage.

Pugach, M. C. (2001). The stories we choose to tell: Fulfilling the promise of qualitative research for special education. Exceptional Children, 67, 439-453.

Rainforth, B., York, J., \& Macdonald, C. (1992). Collaborative team for students with severe disabilities: Integrating therapy and educational services. Baltimore: Brookes.

Roberts, R. N., Rule, S., \& Innocenti, M. (1998). Strengthening the family-professional partnership in services for young children. Baltimore, MD: Brookes.

Salembier, G., \& Furney, K. (1998). Speaking up for your child's future. Exceptional Parent, 28(7), 62-64.

Sandall, S. P, Smith, B. J., McLean, M. E., \& Ramsey, A. L. (2002). Qualitative research in early intervention/early childhood special education. Journal of Early Intervention, 25, 129-136.

Sanders, M. (1999). Improving school, family and community partnerships in urban middle schools. Middle School journal, 31(2), 35-41.

Seidman, I. E. (1991). Interviewing as qualitative research: A guide far researchers in education and the social sciences. New York: Teachers College Press.

Sileo, T. W, \& Prater, M. A. (1998). Preparing professionals for partnerships with parents of students with disabilities: Textbook considerations regarding cultural diversity. Exceptional Children, 64, 513-528.

Soodak, L. C., \& Erwin, E. J. (2000). Valued member or tolerated participant: Parents' experiences in inclusive early childhood settings. Journal of the Association for Persons with Severe Handicaps, 25, 29-41.

Stainback, W., \& Stainback, S. (1989). Using qualitative data collection procedures to investigate supported education issues. Journal of the Association for Persons with Severe Handicaps, 14, 271-277.

Stewart, D. W, \& Shamdasani, P. N. (1990). Focus groups: Theory and practice. Newbury Park, CA: Sage.

Summers, J. A., Steeples, T., Peterson, C., Naig, L., McBride, S., Wall, S., Liebow, H., Swanson, M., \& Stowitschek, J. (2001). Policy and management supports for effective service integration in Early Head Start and Part C programs. Topics in Early Childhood Special Education, 21, 16-30.

Trivette, C. M., Dunst, C. J., Boyd, K., \& Hamby, D. W. (1995). Family-oriented program models, helpgiving practices, and parental control appraisals. Exceptional Children, 62, 237-248. 
Turnbull, A. P., \& Turnbull, H. R. (2001). Families, professionals, and exceptionality: A special partnership (4th ed.). Upper Saddle River, NJ: Merrill/Prentice Hall.

Turnbull, H. R., \& Turnbull, A. P. (2000). Free appropriate public education: The law and children with disabilities (6th ed.). Denver, CO: Love.

Winton, P. J. (2000). Early childhood intervention personnel preparation: Backward mapping for future planning. Topics in Early Childhood Special Education, 20, 87-94

\section{ABOUT THE AUTHORS}

MARTHA BLUE-BANNING, Research Associate Professor; JEAN ANN SUMMERS, Research Associate Professor; H. CORINE FRANKLAND, Research Assistant; LOUISE LORD NELSON, Research Assistant; and GWEN BEEGLE Research Associate Professor, Beach Center on Dis abilities, University of Kansas, Lawrence.

Correspondence concerning this article should be addressed to Martha Blue-Banning, Beach Center on Disabilities, 3130 Haworth, University of Kansas, Lawrence, KS 66045.

The findings reported here are based on research conducted as part of a Core Research Study of the Beach Center on Disabilities, a Rehabilitation Research and Training Center funded by the National Institutes of Disability and Rehabilitation Research, U.S. Department of Education, under Grant No. H133980050 to the University of Kansas, and by an endowment from Ross and Marianna Beach to the University of Kansas. The overall research was a collaborative effort involving numerous contributions from a variety of people. The Core Research focus groups and interviews were conducted and analyzed jointly by Partnership and Family Quality of Life Team members: Gwen Beegle, Martha Blue-Banning, Kim Diehl, H. Corine Frankland, Lisa Mische Lawson, Esther Lerner, Hasheem Mannan, Louise Lord Nelson, Jiyeon Park, David Peres, Denise Poston, Michael B. Ruef, Jean Ann Summers, Ann Turnbull, H. Rutherford Turnbull, and Vicki Turbiville.
Local site coordinators who organized and cofacilitated focus groups were: Debbie Alcoulomre, Terry Caldwell, Louanne King, Kari Lewis, Cheryl Land, Ursula Markey, Sharon Ringwald, and Jamie Young. Finally, transcriptionists, translators, and data entry personnel included: Marianne Graham, Crystal Lewellyn, Jennifer Martin, and David Peres. The authors wish to thank also the members of the core research team who commented on earlier drafts of this article.

The content of this publication does not necessarily reflect the views or policies of the Department of Education or the Ross Beach family, nor does mention of trade names, commercial products, or organizations imply endorsement by the U.S. Government.

This research was supported by a grant from the National Institute on Disability and Rehabilitation Research to the Beach Center on Disability, Grant \#H133B031133. 